ISSN 1420-3049

www.mdpi.com/journal/molecules

\title{
Communication
}

\section{A New Triterpenoid Saponin from Pulsatilla cernua}

\section{Yajuan Xu ${ }^{1,3}$, Lu Bai $^{1}$, Yonghong Liu ${ }^{4}$, Yue Liu ${ }^{1}$, Tunhai Xu ${ }^{2, *}$, Shengxu Xie ${ }^{1}$, Yunshan Si ${ }^{1}$, Haiou Zhou ${ }^{1}$, Tonghua Liu ${ }^{2}$ and Dongming $\mathrm{Xu}^{1}$}

1 Academy of Traditional Chinese Medicine of Jilin Province, Changchun 130021, China;

E-Mail: xyj6492@sohu.com (Y.X.)

2 Department of Traditional Chinese Medicine Chemistry, School of Traditional Chinese Medicine,

Beijing University of Chinese Medicine, Beijing 100102, China

3 College of Pharmacy, Jilin University, Changchun 130021, China

4 Key Laboratory of Marine Bio-resources Sustainable Utilization, South China Sea Institute of Oceanology, Chinese Academy of Sciences, No. 164 West Xingang Road, Guangzhou 510301, China; E-Mail: yonghongliu@scsio.ac.cn (Y.L.)

* Author to whom correspondence should be addressed; E-Mail: thxu@yahoo.com

Received: 1 February 2010; in revised form: 24 February 2010 / Accepted: 9 March 2010 /

Published: 16 March 2010

\begin{abstract}
A new triterpenoid saponin was isolated from Pulsatilla cernua, along with eight known triterpenoids and triterpenoid glycosides. The new compound was identified as 3-O- $\beta$-D-glucopyranosyl- $(1 \rightarrow 4)-\alpha$-L-arabinopyranosyl-bayogenin-28- $\alpha$-Lrhamnopyranosyl-( $1 \rightarrow 4)$ - $\beta$-D-glucopyranosyl-( $1 \rightarrow 6)-\beta$-D-glucopyranosyl ester $(\mathbf{1})$ on the basis of 1D, 2D-NMR techniques, including COSY, HMBC, and HMQC correlations, MS analysis, as well as chemical methods.
\end{abstract}

Keywords: ranunculaceae; Pulsatilla cernua; triterpenoid saponin

\section{Introduction}

Pulsatilla cernua (Thunb.) Bercht. et Opiz is widely distributed in Northeast China. The roots are used as a Traditional Chinese Medicine (TCM) for the treatment of amoebic and bacterial dysentery. Phytochemical studies on this plant were reported previously [1-3]. In the search for new and bioactive components from TCM, we investigated the roots of P. cernua. In the present paper, we report the isolation and structure elucidation of a new triterpenoid saponin from this source. 
Our investigation on the constituents in the ethanolic extract of the plant led to the isolation of a new triterpenoid saponin 1 along with eight known constituents: 3-oxo-hederagenin (2) [4], hederagenin (3) [5], 3-O- $\alpha$-L-arabinopyranosylhederagenin (4) [6], 3-O- $\beta$-D-glucopyranosyl-(1 $\rightarrow 4)-\alpha$ L-arabinopyranosylhederagenin (5) [7], 3-O- $\beta$-D-glucopyranosyl-( $1 \rightarrow 2)-\alpha$-L-arabinopyranosidehederagenin (6) [8], 3-O- $\alpha$-L-arabinopyranosyl-28-O- $\alpha$-L-rhamnopyranosyl-( $1 \rightarrow 4)-\beta$-D-glucopyranosyl- $(1 \rightarrow 6)-\beta$-D-glucopyranosylhederagenin (7) [9], 3- $O-\beta$-D-glucopyranosyl-( $1 \rightarrow 4)-\alpha$-Larabino-pyranosyl-28-O- $\alpha$-L-rhamnopyranosyl- $(1 \rightarrow 4)-\beta$-D-glucopyranosyl- $(1 \rightarrow 6)-\beta$-Dglucopyranosyl-hedera-genin (8) [10] and 3-O- $\beta$-D-glucopyranosyl( $1 \rightarrow 2)-\beta$-Dglucopyranosylhederagenin-28- $O$ - $\alpha$-L-rhamno-pyranosyl-( $1 \rightarrow 4)$ - $\beta$-D-glucopyranosyl-( $1 \rightarrow 6)-\beta$-Dglucopyranosyl (9) [11], The compounds 2, 4, 5, 7-9 were isolated for the first time from P. cernua. Herein, we describe the isolation and structure elucidation of the new compound.

\section{Results and Discussion}

Compound 1, obtained as a white amorphous powder, turned red upon coloration with LiebermannBurchard reagent. The molecular formula $\mathrm{C}_{59} \mathrm{H}_{96} \mathrm{O}_{28}$ was determined by HRESIMS which exhibited a quasi-molecular ion peak at $m / z 1251.6032[\mathrm{M}-\mathrm{H}]^{-}$(calcd. for $\left[\mathrm{C}_{59} \mathrm{H}_{96} \mathrm{O}_{28}-\mathrm{H}\right]^{-}$1251.6010). On acidic hydrolysis, 1 afforded sugar moieties that were identical to authentic samples of arabinose, rhamnose, and glucose. The six tertiary methyl groups $[\delta 0.85,0.86,1.00,1.08,1.14$, and 1.18 (each $3 \mathrm{H}, \mathrm{s})]$, one trisubstituted olefinic proton $\delta 5.41(1 \mathrm{H}, \mathrm{t}-\mathrm{like}, \mathrm{H}-12)$, and a signal at $\delta 3.15(1 \mathrm{H}, \mathrm{dd}, J=3.0,12.5 \mathrm{~Hz}$, $\mathrm{H}-18$ ) observed in the ${ }^{1} \mathrm{H}-\mathrm{NMR}$ spectrum coupled with the information from the ${ }^{13} \mathrm{C}-\mathrm{NMR}$ spectrum (six methyl group carbons at $\delta 15.1,17.5,17.8,24.1,26.7$, and 33.2, and two olefinic carbons at $\delta$ 123.4 and 144.2) indicated that the aglycone possessed an olean-12-ene skeleton. Comparison of the ${ }^{13} \mathrm{C}-\mathrm{NMR}$ data of this aglycone (Table 1$)$ with those of bayogenin $(2 \alpha, 3 \beta, 23$-trihydroxyolean-12-en28-oic acid) [5], showed that the signal for C-3 of 1 was shifted significantly downfield by +4.4 ppm to 83.0, and the C-28 signal was shifted upfield by $-2.0 \mathrm{ppm}$ to 176.6 , while the other signals were almost identical, indicating that the aglycon of 1 was indeed bayogenin. Its ESI-MS spectrum showed a quasi-molecular ion at $m / z 1251$ [M-H] $^{-}$, confirming a molecular weight of 1252 . An ion at $m / z 781$ [M-H-470 (162+162+146)], taken as evidence for the direct elimination of two hexoses and one deoxyhexose, indicated the presence of a trisaccharide unit at C-28 of the aglycone, because the ester glycosidic linkage was more easily broken than the $O$-glycosidic linkage. In addition, the intense ion peaks at $m / z 619$ [M-H-470-162]', 487 [M-H-470-162-132]', suggested the presence of disaccharide unit including arabinose and glucose at C-3 of the aglycone. The ${ }^{13} \mathrm{C}-\mathrm{NMR}$ signals due to sugar moieties were almost superimposable on those of $3-O-\beta$-D-glucopyranosyl- $(1 \rightarrow 4)-\alpha$ - $\mathrm{L}$-arabinopyranosylhederagenin-28- $\alpha$-L-rhamnopyranosyl- $(1 \rightarrow 4)-\beta$-D-glucopyranosyl-( $1 \rightarrow 6)-\beta$-D-glucopyranosyl ester [10]. In a comparison of the ${ }^{13} \mathrm{C}$-NMR signals for sugar moieties of 1 with those of the known saponin of leontoside (3-O- $\beta$-D-glucopyranosyl-( $1 \rightarrow 4)-\alpha$-L-arabinopyranosylhederagenin-28- $\alpha$-Lrhamnopyranosyl-( $1 \rightarrow 4)$ - $\beta$-D-glucopyranosyl-( $1 \rightarrow 6)-\beta$-D-glucopyranosyl ester) [10], all signals due to the sugar moieties of $\mathbf{1}$ were almost superimposable with those of leontoside, indicating the sugar moieties of 1 was same as those of the latter, so the 3-hydroxy and 28-carbonyl groups carried the same disaccharide chain and trisaccharide chain, respectively. Consequently, compound 1 should be a bisdesmosidic saponin in which the disaccharide chain of arabinose and glucose was bound to the 
aglycone by a glycosidic linkage at $\mathrm{C}-3$, while a trisaccharide chain of glucose, glucose, and rhamnose was bound by a glycosidic ester linkage at C-28. The ${ }^{1} \mathrm{H}-$ and ${ }^{13} \mathrm{C}-\mathrm{NMR}$ spectrum of $\mathbf{1}$ exhibited five sugar anomeric protons at $\delta 4.91(1 \mathrm{H}, \mathrm{d}, J=7.0 \mathrm{~Hz}$, ara $\mathrm{H}-1), 5.22(1 \mathrm{H}, \mathrm{d}, J=8.0 \mathrm{~Hz}, \mathrm{glc} \mathrm{H}-1)$, $6.21\left(1 \mathrm{H}, \mathrm{d}, J=8.0 \mathrm{~Hz}, \mathrm{glc}^{\prime} \mathrm{H}-1^{\prime}\right), 4.91\left(1 \mathrm{H}, \mathrm{d}, J=7.9 \mathrm{~Hz}, \mathrm{glc}{ }^{\prime \prime} \mathrm{H}-1^{\prime \prime}\right), 5.82(1 \mathrm{H}$, br s, rha H-1) and carbons at $\delta 95.8,102.9,105.0,106.8$, and 107.3 (Table 1). The methyl carbon signal at $\delta 18.7$ and the doublet methyl proton signal at $\delta 1.71(3 \mathrm{H}, \mathrm{d}, J=6.0 \mathrm{~Hz}$, rha $\mathrm{H}-6)$ indicating the presence of one 6-deoxysugar. These coupling constants indicated that the glycosidic linkage of arabinose, rhamnose were $\alpha$ configuration, and those of glucose were $\beta$ configuration $[12,13]$. The ${ }^{1} \mathrm{H}-$ and ${ }^{13} \mathrm{C}-\mathrm{NMR}$ signals for the aglycone and sugar moieties of 1 was assigned based on the 1D and 2D-NMR spectra (COSY, DEPT, HMQC, and HMBC). The sugar arrangements were determined to be $3-O-\beta$-Dglucosyl- $(1 \rightarrow 4)-\alpha$-L-arabinose by the HMBC which showed the correlations between $\mathrm{H}-1$ of glc at $\delta$ 5.22 and C-4 of ara at $\delta 80.4$, between $\mathrm{H}-1$ of ara at $\delta 4.91$ and C-3 of aglycone at $\delta 83.0$, and 28- $\alpha$-Lrhamnosyl $(1 \rightarrow 4)-\beta$-D-glucosyl $(1 \rightarrow 6)-\beta$-D-glucose by the HMBC which showed the correlations between $\mathrm{H}-1$ of rha at $\delta 5.82$ and C-4 of glc" at $\delta 78.9$, between $\mathrm{H}-1$ of glc" at $\delta 4.91$ and C- 6 of glc' at $\delta 69.4$, between $\mathrm{H}-1$ of $\mathrm{glc}^{\prime}$ at $\delta 6.21$ and C-28 of the aglycone at $\delta 176.6$. On the basis of these evidences, 1 was identified as 3-O- $\beta$-D-glucopyranosyl- $(1 \rightarrow 4)-\alpha$-L-arabinopyranosylbayogenin-28- $\alpha$ L-rhamnopyranosyl-( $1 \rightarrow 4)-\beta$-D-glucopyranosyl-( $1 \rightarrow 6)-\beta$-D-glucopyranosyl ester.

Table 1. ${ }^{1} \mathrm{H}$ - and ${ }^{13} \mathrm{C}-\mathrm{NMR}$ spectral data of compound 1 (recorded at 500/125 $\mathrm{MHz}$ in pyridine- $\mathrm{d}_{5} ; \delta$ in ppm, $J$ in $\mathrm{Hz}$ ).

\begin{tabular}{|c|c|c|c|c|c|}
\hline No. & $\delta \mathrm{c}$ & $\delta_{\mathrm{H}}(J, \mathrm{~Hz})$ & No. & $\delta \mathrm{c}$ & $\delta_{\mathrm{H}}(J, \mathrm{~Hz})$ \\
\hline 1 & 44.4 & & $\mathrm{C}-3$ & & \\
\hline 2 & 71.0 & $4.32(\mathrm{ddd}, 11.8,9.5,3.9)$ & Ara-1 & 106.8 & $4.91(\mathrm{~d}, 7.0 \mathrm{~Hz})$ \\
\hline 3 & 83.0 & 4.24 & 2 & 73.7 & 4.68 \\
\hline 4 & 42.4 & & 3 & 71.4 & 4.27 \\
\hline 5 & 47.9 & & 4 & 80.4 & 4.80 \\
\hline 6 & 18.1 & & 5 & 65.4 & $4.48,4.39$ \\
\hline 7 & 33.0 & & Glc-1 & 107.3 & $5.22(\mathrm{~d}, 8.0)$ \\
\hline 8 & 40.2 & & 2 & 76.0 & 3.92 \\
\hline 9 & 48.7 & & 3 & 78.9 & 4.15 \\
\hline 10 & 37.2 & & 4 & 71.0 & 4.16 \\
\hline 11 & 23.8 & & 5 & 78.6 & 3.89 \\
\hline 12 & 123.4 & 5.41 (t-like) & 6 & 62.6. & $4.29,4.45(\mathrm{~d}, 7.6)$ \\
\hline 13 & 144.2 & & $\mathrm{C}-28$ & & \\
\hline 14 & 42.9 & & Glc-1' & 95.8 & $6.21(\mathrm{~d}, 8.0)$ \\
\hline 15 & 28.4 & & $2^{\prime}$ & 74.2 & 4.10 \\
\hline 16 & 23.5 & & $3^{\prime}$ & 78.2 & 4.19 \\
\hline 17 & 46.3 & & $4^{\prime}$ & 70.4 & 4.25 \\
\hline 18 & 41.8 & $3.15(\mathrm{dd}, 3.0,12.5)$ & $5^{\prime}$ & 78.3 & 4.08 \\
\hline 19 & 47.2 & & $6^{\prime}$ & 69.4 & $4.29,4.62$ \\
\hline 20 & 30.9 & & Glc-1" & 105.0 & $4.91(\mathrm{~d}, 7.9)$ \\
\hline
\end{tabular}


Table 1. Cont.

\begin{tabular}{cccccc}
\hline 21 & 34.1 & & $2^{\prime \prime}$ & 75.5 & 3.89 \\
22 & 32.7 & & $3^{\prime \prime}$ & 76.7 & 4.11 \\
23 & 65.4 & $3.67(\mathrm{~d}, 10.0) 4.54$ & $4^{\prime \prime}$ & 78.9 & 4.34 \\
24 & 15.1 & $1.00(\mathrm{~s})$ & $5^{\prime \prime}$ & 77.3 & 3.81 \\
25 & 17.5 & $1.08(\mathrm{~s})$ & $6^{\prime \prime}$ & 61.4 & $4.06,4.21$ \\
26 & 17.8 & $1.14(\mathrm{~s})$ & $\mathrm{Rha}-1$ & 102.9 & $5.82(\mathrm{br}, \mathrm{s})$ \\
27 & 26.7 & $1.18(\mathrm{~s})$ & 2 & 72.7 & 4.61 \\
28 & 176.6 & & 3 & 72.9 & 4.50 \\
29 & 33.2 & $0.85(\mathrm{~s})$ & 4 & 74.0 & 4.27 \\
30 & 24.1 & $0.86(\mathrm{~s})$ & 5 & 70.9 & 4.85 \\
& & & 6 & 18.7 & $1.71(\mathrm{~d}, 6.0)$ \\
\hline
\end{tabular}

Figure 1. Structure and key HMBC correlations $(\mathrm{H} \rightarrow \mathrm{C})$ of compound $\mathbf{1}$.

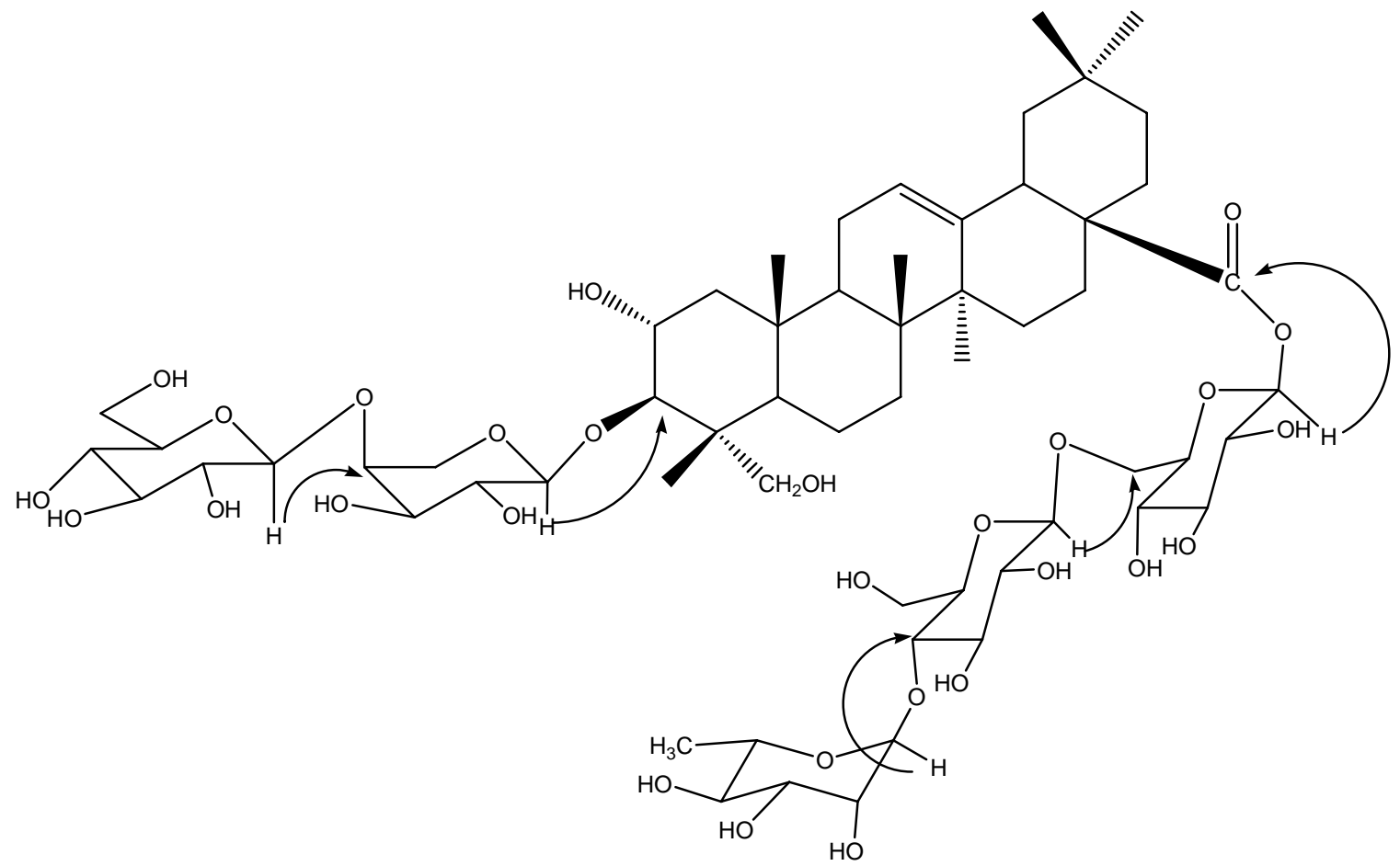

\section{Experimental}

\subsection{General}

The melting point was determined on a Kofler-microscope apparatus and is uncorrected. The IR spectra were measured on a Y-Zoom scroll Fourier Transform infrared (FTIR) spectrometer using KBr discs. The ESI-MS was recorded on LCQ-1700 ESI-MS instrument made by the Finnigan (USA). The NMR spectra were obtained on Bruker AM-500 instrument, using TMS as internal standard. HPLC (600E HPLC, Waters, USA) was performed using a ODS column (Shim-park PREF-ODS, $250 \times 4.6 \mathrm{~mm}$ ). Column chromatography was performed on silica gel (200-300 mesh, Qingdao Oceanic Chemical Industry China) and ODS reversed silica gel (250 $\times 25 \mathrm{~mm}$, Nacalai Tesque, Kyoto, 
Japan). Macroporous resin $\mathrm{D}_{101}$ made in Nankai University, Tianjin. TLC was conducted on silica gel $60 \mathrm{~F}_{254}$ (Merck). Spots were detected after spraying with $10 \% \mathrm{H}_{2} \mathrm{SO}_{4}$.

\subsection{Plant Material}

The roots of P. cernua were collected in August 2007, near Yanji city, Jilin Province, China and identified by Professor Minglu Deng, Changchun College of Traditional Chinese Medicine. A voucher specimen (20070827) was deposited in Academy of Traditional Chinese Medicine and Material Medica of Jilin Province, Changchun, China.

\subsection{Extraction and Isolation}

The dry roots of $P$. cernua $(5 \mathrm{~kg})$ were extracted with $80 \%$ EtOH $\left(70-80{ }^{\circ} \mathrm{C}, 3 \times 15 \mathrm{~L}\right.$, $4 \mathrm{~h}$, each). The $80 \%$ EtOH solution was heated on steam bath to remove EtOH. The water solution was chromatographed over a $\mathrm{D}_{101}$ macroporous resin column $(10 \times 80 \mathrm{~cm})$, eluted successively with $10 \%$ $\mathrm{EtOH}, 40 \% \mathrm{EtOH}, 80 \% \mathrm{EtOH}$. The $40 \% \mathrm{EtOH}$ eluate and $80 \% \mathrm{EtOH}$ eluate were evaporated to dryness to give $40 \%$ EtOH extract (120 g), and 80\% EtOH extract (26 g), respectively. The $40 \% \mathrm{EtOH}$ crude extract (60 g) was chromatographed on silica gel (1.2 kg, 200 mesh ) with $\mathrm{CHCl}_{3}-\mathrm{MeOH}-\mathrm{H}_{2} \mathrm{O}$ [(50:5:1, lower layer $\rightarrow$ 10:5:1, lower layer), to afford five fractions (fr.1 (1.2 g), fr.2 (0.35 g), fr.3 (0.8 g), fr.4 (0.6 g), fr.5 (0.65 g). Fr.1, fr.2 and fr.4 were dissolved in $\mathrm{MeOH}$ to give compounds 2 $(1.0 \mathrm{~g}), 3(118 \mathrm{mg})$, and $4(46 \mathrm{mg})$, respectively. Fr. 3 was further subjected to silica gel column chromatography $\left[\mathrm{CHCl}_{3}-\mathrm{MeOH}-\mathrm{H}_{2} \mathrm{O}(30: 3: 1\right.$, lower layer $\rightarrow 10: 3: 1$, lower layer $\rightarrow$ 6:4:1) $\rightarrow \mathrm{EtOH}]$, to obtain four fractions (fr.4-1-fr.4-5). Fr.4-4 was dissolved in $\mathrm{MeOH}$ to give 5 (102 mg). Fr.5 was purified by reversed-phase silica gel column chromatography [ $\left.\mathrm{MeOH}-\mathrm{H}_{2} \mathrm{O}(70: 30 \rightarrow 90: 10) \rightarrow \mathrm{MeOH}\right]$ to give 6 (45 mg). The $80 \% \mathrm{EtOH}$ extract $(26 \mathrm{~g}$ ) was chromatographed on silica gel ( $0.6 \mathrm{~kg}$, 200 mesh) with $\mathrm{CHCl}_{3}-\mathrm{MeOH}-\mathrm{H}_{2} \mathrm{O}$ [ (50:10:1, lower layer $\rightarrow$ 10:10:1, lower layer)], to afford four fractions [fr.1 (1.4 g), fr.2 (1.2 g), fr.3 (0.8 g), fr.4 (0.6 g)]. Fr.1 was purified by reversed-phase silica gel column chromatography [MeOH- $\mathrm{H}_{2} \mathrm{O}(60: 40 \rightarrow 90: 10) \rightarrow \mathrm{MeOH}$ ] to give two fractions [fr.1 $(1.0 \mathrm{~g})$, fr.2 $(0.7 \mathrm{~g})$ ]. Fr. 1 was dissolved in $\mathrm{MeOH}$ to give compounds $1(0.8 \mathrm{~g})$ and 9 (47 mg). Fr.2 was further subjected to silica gel column chromatography $\left[\mathrm{CHCl}_{3}-\mathrm{MeOH}-\mathrm{H}_{2} \mathrm{O}(30: 5: 1\right.$, lower layer $\rightarrow 10: 5: 1$, lower layer $\rightarrow 6: 4: 1) \rightarrow$ EtOH], to furnish five fractions (fr.2-1-fr.2-5). Fr.2-2 was dissolved in $\mathrm{MeOH}$ to give 7 (65 mg). Fr.2-4 was further subjected to silica gel column chromatography $\left[\mathrm{CHCl}_{3}-\mathrm{MeOH}-\right.$ $\mathrm{H}_{2} \mathrm{O}(30: 5: 1$, lower layer $\rightarrow 10: 5: 1$, lower layer $\rightarrow 6: 4: 1) \rightarrow$ EtOH] to give 8 (160 mg).

\subsection{Acid Hydrolysis of 1}

Compound $1(10 \mathrm{mg})$ was heated with $2 \mathrm{M} \mathrm{HCl}-\mathrm{MeOH}(10 \mathrm{~mL})$ under reflux for $3 \mathrm{~h}$. The reaction mixture was diluted with $\mathrm{H}_{2} \mathrm{O}$ and extracted with $\mathrm{CHCl}_{3}$. The water layer was neutralized with $\mathrm{Na}_{2} \mathrm{CO}_{3}$, concentrated, and subjected to TLC analysis with authentic glucose, arabinose, rhamnose, and developed with $\mathrm{CH}_{2} \mathrm{Cl}_{2}-\mathrm{MeOH}-\mathrm{H}_{2} \mathrm{O}$ (15: 6:1). Detection was carried out with aniline phthalate spray. 


\subsection{Characterization of Compound 1}

White powder, $\mathrm{mp} 221-223{ }^{\circ} \mathrm{C}$; $[\alpha]_{\mathrm{D}}{ }^{20}-37.7^{\circ}$ (c 0.30; MeOH); HRESIMS $m / z$ found 1251.6032 [M$\mathrm{H}^{-}$(calcd. for [ $\left.\left.\mathrm{C}_{59} \mathrm{H}_{96} \mathrm{O}_{28}-\mathrm{H}\right]^{-}, 1251.6010\right)$. ESIMS m/z 1251 [M-H]', 781 [M-H-470 (162+162+146)]', 619 [M-H-470-162] $]^{-}, 487[\mathrm{M}-\mathrm{H}-470-162-132]^{-},{ }^{1} \mathrm{H}-\mathrm{NMR}\left(500 \mathrm{MHz}\right.$, pyridine-d $\left.\mathrm{d}_{5}\right) \delta(\mathrm{ppm}), J(\mathrm{~Hz})$ and ${ }^{13} \mathrm{C}-\mathrm{NMR}\left(125 \mathrm{MHz}\right.$, pyridine- $\left.\mathrm{d}_{5}\right) \delta(\mathrm{ppm})$ : see Table 1.

\section{Conclusions}

A new triterpenoid saponin, 3- $O-\beta$-D-glucopyranosyl-( $1 \rightarrow 4)-\alpha$-L-arabinopyranosylbayogenin-28- $\alpha$ L-rhamnopyranosyl-( $1 \rightarrow 4)-\beta$-D-glucopyranosyl-( $1 \rightarrow 6)-\beta$-D-glucopyranosyl ester $(\mathbf{1})$, was isolated from the roots of from P. cernua. Most of the terpenoid saponins are oleane-type (oleanolic acid and hederagenin) from the genus Pulsatilla. This is the first time terpenoid saponin with $2 \alpha$-hydroxy in its aglycone (bayogenin) has been isolated from the genus Pulsatilla. This finding is meaningful for the chemotoxonomy of this species.

\section{Acknowledgements}

The authors are supported by the Key Project of Chinese Ministry of Education (No 108132) and New Century Excellent Talents in University (NCET-08-0746) and Cooperation Program of Beijing Municipal Education Commission.

\section{References}

1. Zhang, Q.W.; Ye, W.C.; Che, C.T.; Zhao, S.X. Triterpene saponins from pulsatilla cernua. Acta Pharm. Sin. 2000, 35, 756-759.

2. Xu, T.H.; Xu, Y.J.; Han, D.; Zhao, H.F.; Xie, S.X.; Xu, D.M. Triterpenoid saponins from Pulsatilla cernua (Thunb.) Bercht. et Opiz. J. Integr. Plant Biol. 2007, 49, 202-206.

3. Xu, T.H.; Xu, Y.J.; Li, H.X.; Han, D.; Zhao. H.F.; Xie, S.X.; Li, Y.; Niu, J.Z.; Si, Y.S.; Xu, D.M. Two new triterpenoid saponins from Pulsatilla cernua (Thunb.) Bercht. et Opiz. J. Asia Nat. Prod. Res. 2007, 9, 705-711.

4. Miyakoshi, M.; Shirasuna, K.; Hirai, Y.; Shingu, K.; Isoda, S.; Shoji, J.; Ida, Y.; Shimizu, T. Triterpenoid Saponins of Acanthopanax nipponicus leaves. J. Nat. Prod. 1999, 62, 445-448.

5. Mahato, S.B.; Kundu, A.P. ${ }^{13}$ C NMR spectra of pentacyclic triterpenoids-a compilation and some salient features. Phytochemistry 1994, 37, 1517-1575.

6. Bhandari, P.; Gray, A.; Rastogi, R.P. Triterpenoid saponins from Caltha palustris. Planta Med. 1987, 53, 98-100.

7. Kang, S.S. Saponins from the roots of Pulsatilla koreana. Arch. Pharm. Res. 1989, 12, $42-47$.

8. Kawai, H.; Kuroyanagi, M.; Umehara, K.; Ueno, A.; Satake, M. Studies on the saponins of Lonicera japonica Thunb. Chem. Pharm. Bull. 1988, 36, 4769-4775.

9. Hahn, D.R.; Oinaka, T.; Kasai, R.; Tanaka, O. Saponins from Leaves of Kalopanax pictum var. maximowiczii, a Korean Medicinal Plant. Chem. Pharm. Bull. 1989, 37, 2234-2235.

10. Li, X.C.; Wang, D.Z.; Wu, S.G.; Yang, C.R. Triterpenoid saponins from pulsatilla campanella. Phytochemistry 1990, 29, 595-599. 
11. Grishkovets, V.I.; Sobolev, E.A.; Shashkov, A.S.; Chirva, V.Y. Triterpene glycosides of Fatsia japonica. I. Isolation and structure of glycosides from Fatsia japonica seeds. Chem. Nat. Compd. 2000, 36, 166-169.

12. Agrawal, P.K. NMR spectroscopy in the structural elucidation of oligosaccharides and glycosides. Phytochemistry 1992, 31, 3307-3330.

13. Agrawal, P.K.; Jain, D.C.; Gupta, R.K.; Thakur, R.S. Carbon-13 NMR spectroscopy of steroidal sapogenins and steroidal saponins. Phytochemistry 1985, 24, 2479-2496.

Sample Availability: Samples of the compounds are available from the authors.

(C) 2010 by the authors; licensee Molecular Diversity Preservation International, Basel, Switzerland. This article is an open-access article distributed under the terms and conditions of the Creative Commons Attribution license (http://creativecommons.org/licenses/by/3.0/). 